\title{
The Open Science Network in Ethnobiology: Growing the Influence of Ethnobiology
}

\author{
Cassandra L. Quave ${ }^{1,2^{*}}$, Keri Barfield ${ }^{3}$, Nanci Ross ${ }^{4}$, Karen C. Hall ${ }^{3}$
}

Author address: ${ }^{1}$ Center for the Study of Human Health, Emory University, 550 Asbury Circle, Candler Library 107, Atlanta, GA 30322, USA. ²Department of Dermatology, Emory University School of Medicine, 1518 Clifton Rd NE, CNR Bldg., Room 5035, Atlanta, GA 30322, USA. ${ }^{3}$ Botanical Research Institute of Texas, 1700 University Dr., Fort Worth, TX 76107, USA. ${ }^{4}$ Drake University, Biology Department, Olin Hall, 2507 University, Des Moines, IA 50311, USA.

Corresponding author : cquave@emory.edu

Received: January 6, 2015

Published: January 22, 2015
Volume: $6(1): 1-4$

(C) 2015 Society of Ethnobiology
The literature is rife with calls for a path to connect students, especially non-traditional and minority students, with science (see, for example, Bennett 2005, Henderson et al. 2012, Loving 1998, McClatchey et al. 1999). Since ethnobiology is the investigation of the interconnectedness of humans and environments, we argue that this makes it an ideal mechanism to guide students to see their relationship with both science and the natural world, a key component in stimulating students' interest. Yet ethnobiology is a relatively new field of study and ethnobiology scholars, often isolated in their disparate academic homes, can greatly benefit from collaborating on the development of ethnobiology education and resources.

The Open Science Network in Ethnobiology (OSN) is a dynamic "open science" network that promotes ethnobiological education through the use of web-based technologies and the continual exchange of educational techniques, materials, and experiences across institutional and international borders. The project was the brainchild of Kim Bridges and Will McClatchey, building on their successful 'Segues to Science' grant (2015). They partnered with Pat Harrison (currently interim CEO of Botanical Research Institute of Texas) to write the original OSN grant funded (2009-2014) by the United States National Science Foundation (NSF) and the project is also a Research Coordination Networks in Biological Sciences (RCN) Undergraduate Biology Education (UBE) award recipient. The co-authors of this editorial make up the elected officers of the current OSN governing board.
The OSN was founded on the principle of an "open-philosophy," with core efforts focused on supporting the development of a perpetual human network generating science curricula through team efforts of universities, science institutions, educators, and students. Layered alongside the human network, OSN formed a virtual network of resources using an open-group evaluation model similar to open-source software (Figure 1). Unlike a static repository of information, the web-based system's technological capabilities are flexible enough to house the collective knowledge of both expert and user and change as knowledge and needs evolve. The broad project goals were three-fold:

1) Build an interdisciplinary network to advance undergraduate biology education specifically as it regards the promotion or inclusion of ethnobiologically-based content.

2) Build a web portal to facilitate continual exchange of educational techniques, materials, and experiences across institutional and international borders.

3) Develop curriculum models that engage educators and students in scientific inquiry through Ethnobiology.

In line with these goals, OSN has hosted 15 collaborative workshops, engaging a wide diversity of individuals, including botanists, ecologists, anthropologists, ethnobiologists, foresters, undergraduate students, graduate students, and ethnobiology educators in community colleges, universities, Native American colleges, and botanical research institutions. The collective outcomes of these network building events are extensive, and most notably include: 


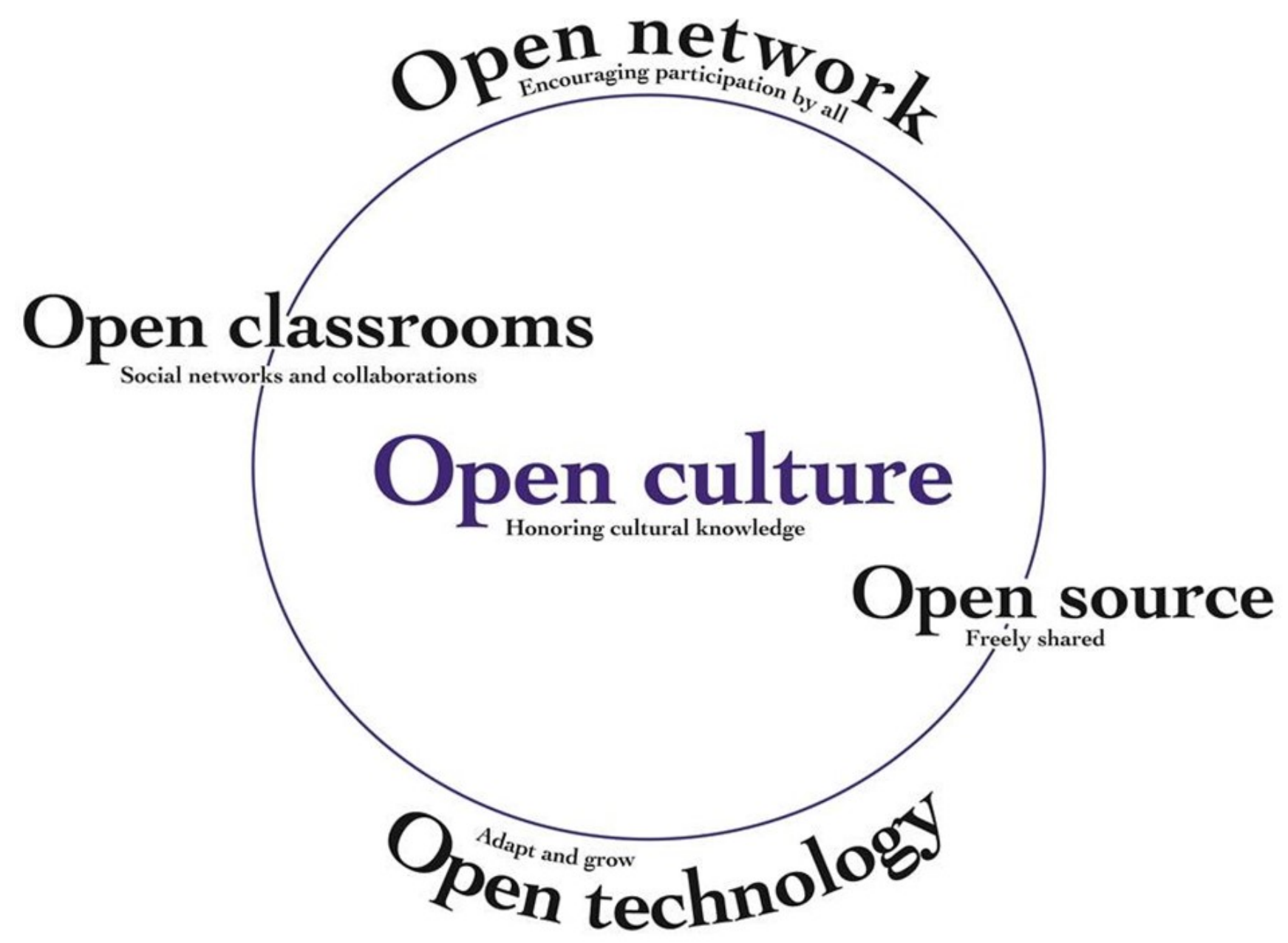

Figure 1. A conceptual framework for the OSN in Ethnobiology.

1) Creation of the working document "The Vision and Change in Undergraduate Ethnobiology Education in the U.S.A.: Recommended Curriculum Assessment Guidelines" (McClatchey et al. 2013), that was written in response to an increasing demand for curricula in ethnobiology. Written over a series of meetings, this document evolved from the interactions and input from 46 OSN workshop participants, which self-identified as anthropologists (11), biologists (12), botanists (25), ecologists (12), area studies scientists (4) and ethnobotanists/ethnoecologists (31). It is modeled after the document of a similar name (Brewer and Smith 2011) that was a call to action from the American Association for the Advancement of Science (AAAS) for improving science curriculum development in undergraduate education. For OSN, the ethnobiology working document contributes the missing element in most science education, the human component, and highlights the true interdisciplinarity of modern science.

2) Launch of the EconBotEd Digital Library with the Society for Economic Botany, hosted by the LifeDiscoveryEd Digital Library, and which will serve, together with the group's website (OSN 2015), as the repository for OSN peer-reviewed ethnobiology educational materials. One of OSN's immediate aims is to grow this resource through the contributions of our membership.

3) Inclusion of regular teaching workshops within meetings of the Society for Economic Botany.

4) Production of the edited book, Innovative Strategies for Teaching in the Plant Sciences, which is composed of chapters contributed by OSN members and on 
topics actively discussed in prior collaborative workshops (Quave 2014).

In addition to hosting interactive workshops, OSN has placed a significant amount of effort into outreach, making contact with and actively engaging 484 individuals from 57 academic institutions in OSN events. OSN related papers, workshops and sponsored booths have been presented at various scientific conferences, including meetings of the Society of Ethnobiology, Society for Economic Botany, International Society of Ethnobiology, Ecological Society of America, Botanical Society of America, American Society of Plant Biologists, Association of Southeastern Biologists, Life Discovery- Doing Science Education, Rocky Mountain Sustainability and Science Network, and Minorities in Agriculture, Natural Resources and Related Sciences. As a consequence of the group's activities and increased networking, 31 peer-reviewed papers were published, 2 books written, and 4 grants submitted.

OSN participants are passionate about ethnobiology and teaching. An intrinsic component of ethnobiology research is a recognition that priceless knowledge of the natural world is discovered through a myriad of cosmologies beyond the Western scientific approach and that this knowledge is carried and passed down by many "non-scientific" cultures. As both scholars and educators, in many cases our teaching activities have been positively transformed by observations of the transfer of knowledge within cultures other than our own (Hunn 2014). While these experiences enrich the lives of ethnobiologists, perhaps their greatest potential is toward informing positive change within classrooms that can translate to the broader world. Since it is likely that no single cultural group holds the key to human survival, it is important that we continue to teach and learn from each other in respectful, honest, and open ways.

Some of the more significant, if perhaps less tangible, outcomes of OSN have been the growth of integral relationships among the membership. While more difficult to quantify, this particular outcome resonates at the core of the OSN philosophy of sharing and promoting the overall good of the discipline. For example, through OSN events and activities over the past five years, a number of early career ethnobiologists have greatly benefited as scientists and educators from interactions with elder mentors, peers and network resources (in particular, teaching resources). Collaborative research projects, teaching initiatives, field schools, research papers, grant proposals, and lasting friendships have been born. The lessons learned through these interactions have not only aided those engaged in OSN activities, but have also impacted the broader scientific and academic community as the OSN membership has brought back lessons learned to integrate into activities at their own institutions.

Moving forward, OSN has put a lot of thought into how to sustain our present momentum in the absence of the significant funding that has supported the network until now. At its 2013 annual meeting, OSN formed its own free-standing organization upon a unanimous vote of all attending members. The OSN adopted Bylaws and installed the organization's first Board of Directors. In its Bylaws, the mission of OSN is to support improvements and development of ethnobiology educational opportunities with many communities, institutions, organizations and individuals. The stated objectives of OSN are to:

1) Support research-based teaching and learning practices.

2) Make recommendations for curriculum standards for ethnobiology courses and program.

3) Maintain an open-system, open-access approach to sharing resources as the foundational structure of OSN.

Like all good projects, the collective efforts of OSN have evolved with experience and there are clear challenges before us. This includes the primary challenge of obtaining peer-reviewed curricular materials from academics who generally receive no reward for their participation. A full accounting of challenges and solutions is out of the scope of this article, though McClatchey and Bridges (2014) have covered the topic well.

Ethnobiology, as defined by the Society of Ethnobiology, is "the scientific study of dynamic relationships among peoples, biota and environments." This short, but sweeping definition, speaks volumes to the inherent interdisciplinarity of ethnobiology, which supports research that spans a broad spectrum from the pure to applied. The future success of OSN is highly dependent upon the foundation of a robust and well-represented network of diversity in ethnobiology. The OSN exists primarily to provide rigor in ethnobiological teaching, no matter the disciplinary home in which it resides. We believe OSN can achieve this aim while also retaining a philosophy 
of openness to other ways of seeing the world. It is with this document we particularly ask for your participation with the organization.

This year, OSN will host the "Teaching Tuesday" educational workshops and an evening event at the annual meeting of the Society for Economic Botany, to be held in Clanwilliam, South Africa. OSN will host its annual meeting this year in conjunction with the Ecological Society of America, to be held in Baltimore, MD. We would like to invite all interested individuals to attend our workshops this year to be held in conjunction with these meetings and to visit the OSN website for more information and links to educator resources. In the beginning, interdisciplinarity was at the heart of the original grant that funded the OSN. It continues to be our strength - please help us grow the influence of this interesting and important discipline!

\section{References Cited}

Bennett, B. C. 2005. Ethnobotany Education Opportunities, and Needs in the U.S.A. Ethnobotany Research \& Applications 3:113-121.

Brewer, C. A., and D. Smith, eds. 2011. Vision and Change in Undergraduate Biology Education: A Call to Action. American Association for Advancement of Science, Washington, DC.

Ethnobotany Segues to Science. Available at: $\underline{\text { https:// }}$ sites.google.com/site/seguestoscience/history. Accessed on January 9, 2015.

Henderson, F., I. Vandebroek, M. J. Balick, and E. J. Kennelly. 2012. Ethnobotanical Research Skills for Undergraduate Students of Underrepresented Minorities in STEM Disciplines. Ethnobotany Research and Applications 10:389-402.

Hunn, E. 2014. To Know Them is to Love Them. Ethnobiology Letters 5:146-150.

Loving, C. C. 1998. Cotes' Multicultural Empowerment
Model and Generative Teaching and Learning in Science. Science and Education 7:533-552.

McClatchey, W. C., A. Paul, T. Flaster, and V. McClatchey. 1999. An Evaluation of Educational Trends in Economic and Ethnobotany. Ethnobotany Educational Publication Series $1: 1-21$.

McClatchey, W. C., and K.W. Bridges. 2014. Lessons Learned in Development of an Interdisciplinary Science Curriculum Support Organization. In Innovative Strategies for Teaching in the Plant Sciences, edited by C.L. Quave, pp. 21-31. Springer Press, New York, NY.

McClatchey, W. C., G. E. Wagner, K. Hall, and P. D. Harrison, eds. 2013. Vision and Change for Undergraduate Ethnobiology Education in the U.S.A. Open Science Network in Ethnobiology. Available at: https://drive.google.com/file/ d/0B6kZcBxUaY3eMjcxZml2VkxSTmM/edit?pli=1 Accessed on January 6, 2015.

OSN. 2015. The Open Science Network in Ethnobiology. Available at: http://www.opensciencenetwork.org/ Accessed on January 13, 2015.

Quave, C. L., ed. 2014. Innovative Strategies for Teaching in the Plant Sciences. Springer Press, New York, NY.

\section{Biosketches}

Cassandra Quave is an Assistant Professor of Dermatology and Human Health at Emory University with research interests in medical ethnobotany.

Keri Barfield is the Research Programs Manager at the Botanical Research Institute of Texas with research interests in ecology, botany, and ethnobiology education.

Nanci Ross is an Assistant Professor of Biology at Drake University. Her research interests are historical ecology and ecological ethobotany.

Karen Hall is an Applied Ecologist with the Botanical Research Institute of Texas. Her research foci is urban resilience and ethnobotany. 